67. Шоков А.Ф. Неолитические находки на Дону // Известия Воронежского государственного педагогического института. T. XXVI. Воронеж: Изд-во ВГПИ, 1958. С. 181-187.

68. Кашина Е.А. Долблёная лодка с Дона в экспозиции Государственного исторического музея: история находки и проблема датировки // Археология, этнография и антропология Евразии. 2017. Т. 45, № 1. C. $76-82$.

69. ОПИ ГИМ. Ф. 487. Ед. хр. 2.

70. ОПИ ГИМ. Ф. 487. Ед. хр. 101.

71. Рогачёв А.Н. Костёнки IV - поселение древнекаменного века на Дону // Материалы и исследования по археологии СССР. 1955. № 45. 164 с.
Центральное Черноземье в биографии и исследованиях...

72. Формозов А.А. М.Е. Фосс и проблема неолитических культур // Очерки истории отечественной археологии. Вып. ІІ / отв. ред. А.А. Формозов, И.С. Каменецкий. М.: Богородский печатник, 1998. С. 214-228.

73. Фосс М.Е. Древнейшая история севера Европейской части СССР // Материалы и исследования по археологии СССР. 1952. № 29. 280 с.

74. Фосс М.Е. Неолитическая стоянка Бисерово Озеро // Краткие сообщения Института истории материальной культуры. 1959. Вып. 75. С. 26-39.

Исследование выполнено при финансовой поддержке РФФИ и Правительства Воронежской области в рамках научного проекта № 18-49360007.

\title{
CENTRAL CHERNOZEMIE IN THE BIOGRAPHY AND RESEARCHES OF M.E. FOSS
}

(C) 2019

\author{
Akinshin Aleksandr Nikolayevich, candidate of historical sciences, \\ associate professor of History of Russia Department \\ Voronezh State University (Voronezh, Russian Federation) \\ Bessudnov Aleksandr Nikolayevich, candidate of historical sciences, \\ associate professor of Russian and World History Department \\ Lipetsk State Pedagogical P. Semenov-Tyan-Shansky University (Lipetsk, Russian Federation) \\ Zakharova Elena Yurievna, doctor of historical sciences, \\ associate professor of Archaeology and Ancient History Department \\ Voronezh State University (Voronezh, Russian Federation)
}

Abstract. The following paper deals with the research activity of Maria Evgenyevna Foss in Central Chernozemie. Considering the fact that Voronezh played a decisive role in the fate of M.E. Foss (she studied here, formed as a person, acquired the first experience of archaeological research, museum work, collected an extensive data bank on collections from the regional sites, to which subsequently repeatedly referred to herself and such famous archaeologists as T.B. Popova, O.A. Krivtsov-Grakov, V.P. Levenok, N.N. Gurina, A.D. Pryakhin, A.T. Sinyuk and others), special attention is paid to biographical information reflecting the connection of the Foss family with Voronezh. It's the first time when the results of the analysis of documents from the SAVO funds with the additions of Margarita Foss Maria Evgenyevna's niece - are published. Without challenging the opinion that has been established in modern Neolithic studies that M.E. Foss prioritized sites and cultures of the forest zone, it is proved that her contribution to the study of the antiquities of the forest-steppe is much greater than it seems to the modern archaeological community. It was based on archival sources (from the funds of IA RAS, SA IHMC RAS, DFR SHM, Michurinsk Museum (Tambov Region)) and special literature. The results of her research of Shelaevo dunes (modern Belgorod Region), on settlements of different times in Voronezh (burial ground «Chastye kurgany», the site of Otrozhka, the site of Kostenki IV (Aleksandrovka)) and Tambov (sites of Podzorovo and Glinishche) regions have not lost their significance up to the present time.

Keywords: Voronezh State University; Voronezh branch of MAI; Eastern European forest-steppe; history of archaeology; burial ground «Chastye kurgany»; Neolithic; Foss Maria Evgenyevna; site of Otrozhka; Podzorovskaya site; site of Kostenki IV (Aleksandrovka); Glinishche site; Central Chernozemie; Shelaevo sites; Bronze age.

УДК 902/904

DOI $10.24411 / 2309-4370-2019-12203$

Статья поступила в редакцию 18.02.2019

\section{ГОНЧАРНЫЕ ТРАДИЦИИ НАСЕЛЕНИЯ ЛЕВШИНСКОГО ЭТАПА КАМСКОЙ НЕОЛИТИЧЕСКОЙ И НОВОИЛЬИНСКОЙ РАННЕЭНЕОЛИТИЧЕСКОЙ КУЛЬТУР}

(C) 2019

Андреева Ольга Викторовна, лаборант научно-исследовательской части
Самарский государственный социально-педагогический университет (2. Самара, Российская Федерация)
Батуева Надежда Сергеевна, специалист научного отдела
Пермский государственный гуманитарно-педагогический университет (2. Пермь, Российская Федерация)

Аннотация. В статье в рамках историко-культурного подхода к изучению гончарства проанализированы комплексы позднего (левшинского) этапа камской неолитической культуры и ранние энеолитические керамические комплексы новоильинской культуры Среднего и Верхнего Прикамья. Ранее авторами проводились подобные исследования, но без добавления в сравнительный анализ данных об орнаментации посуды. В ходе работы выделены наиболее устойчивые традиции отбора сырья: для камской культуры характерно преимущественное использование илистой глины, для изготовления новоильинской керамики в равных долях использовали глину и илистую глину. Примечательно, что для изготовления камской керамики, кроме использования сырья в естественно увлажненном состоянии, его также и дробили, в новоильинской посуде данная 
традиция отсутствует. Сходным для обеих культур является использование в основном незапесоченного (пластичного) сырья. В итоге выяснилось, что население Прикамья раннего энеолита складывалась на основе генезиса местного неолитического населения - носителей камской культуры с пришлым (Поволжским) населением. На данный факт могут указывать различия в навыках подготовки пластичного сырья, подготовке минеральной примеси для составления формовочной массы, а также приемы нанесения орнамента.

Ключевые слова: археология; неолит; ранний энеолит; историко-культурный подход; технико-технологический анализ; Прикамье; камская культура; левшинский этап; новоильинская культура; орнамент; археологическая керамика; исходное пластичное сырье; формовочная масса; глина; илистая глина; шамот; органический раствор.

\section{Введение}

В рамках историко-культурного подхода керамика рассматривается как результат труда гончара [1]. При этом, учитываются все стадии производства от отбора материала до обработки поверхности сосудов. В данной статье мы сравниваем технологию изготовления (отбор исходного пластичного сырья и составление формовочной массы) с техникой орнаментации керамики двух преемственных культур Прикамья - неолитической камской и раннеэнеолитической новоильинской.

Камская культура была выделена О.Н. Бадером по коллекциям таких памятников, как Хуторская стоянка, Боровое Озеро I, Кряжская и др. Исследователи отмечают следующие характерные черты посуды: полуяйцевидные сосуды с венчиками, скошенными внутрь с наплывом на внутренней стенке, орнаментированные гребенчатым штампом, с плотной орнаментацией. Наиболее распространены отпечатки гребенчатого штампа, выполненные оттискиванием или шаганием («шагающая гребенка») (рис. 1-2) [2].

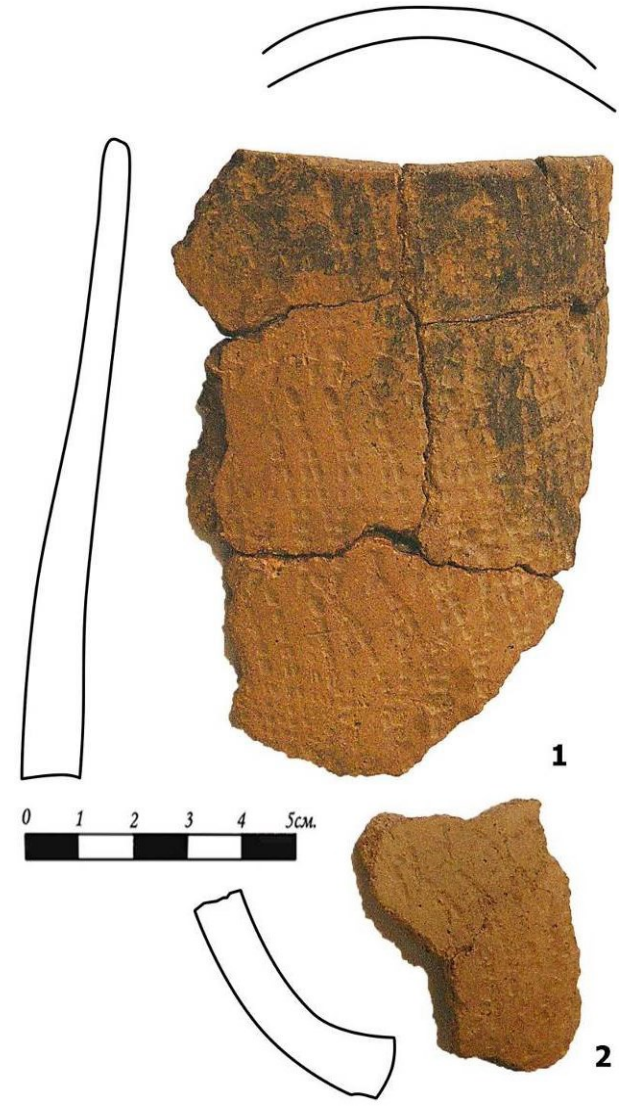

Рисунок 1 - Керамика камской культуры. 1-2- шагающая гребенка

Новоильинская культура также была выделена О.Н. Бадером, на основе характеристики памятников устья р. Чусовой и Средней Камы. Сосуды новоильинской посуды отличает полуяйцевидная форма.
Профилированность сосудов слабая, шейка прямая, но встречается слабо открытая и закрытая. Новоильинская посуда украшалась гребенчатым штампом (коротким, средним, длинным), оттисками гладкого штампа, ямками и ногтевидными насечками. В основном керамика орнаментирована зонально. Основные мотивы орнамента: горизонтальный зигзаг, горизонтальные ряды прямых и наклонных оттисков гребенчатого штампа, решетка, ромбы, на части сосудов встречается орнаментальный мотив в виде флажка (рис. 3) [3].

\section{Методы исследования}

Исследование базировалось на принципах историко-культурного подхода, созданного А.А. Бобринским [1; 4] и дополненного последователями [5-9]. Данный метод основан на изучении и выявлении приемов труда древних гончаров. Основная задача историко-культурного подхода полная или частичная реконструкция процесса изготовления керамической посуды [1]. В ходе изучения керамики с помощью бинокулярной микроскопии выявляются следы работы гончара, которые представлены на поверхности и изломе сосуда [4]. Трактовка технологических следов производится путем их сравнения с известными признаками приемов работы древних гончаров [1], а также с эталонами Самарской экспедиции по экспериментальному изучению древнего гончарства $[5 ; 6]$.

Также в рамках историко-культурного подхода проходит изучение орнаментации керамики. Орнамент - это понятие для обозначения «узора, как повторяющегося элемента». Орнамент характеризуется повторяемостью, структурностью [10, с. 164].

В орнаменте в качестве простейшей, неделимой части принято рассматривать элемент, т.е. один отпечаток орнаментира. [11, с. 88-90].

\section{Обсуждение результатов}

\section{Камская культура}

Исследовалась керамика камской культуры позднего (левшинского) этапа. Анализу были подвергнуты фрагменты от 48 сосудов из коллекций следующих памятников: Заборное Озеро I (9), Усть-Залазнушка (3). Чернашка (6), Усть-Паль (5), Чернушка (2), Базов Бор (9), Чашкинское Озеро VI (14).

При изучении навыков отбора исходного пластичного сырья было выявлено, что для изготовления посуды гончары камской культуры использовали глины - (42\%) и илистые глины (58\%), сырье в 64\% образцов применялось в естественно увлажненном состоянии. Применение дробления было больше характерно для глин, которые в 50\% случаев замешивались в дробленом состоянии, а илистые глины предварительно высушивали и дробили только в 20\% случаев. Глины в $65 \%$ случаев использовались незапесоченными / слабозапесоченными, а илистые глины - в $96 \%$. 

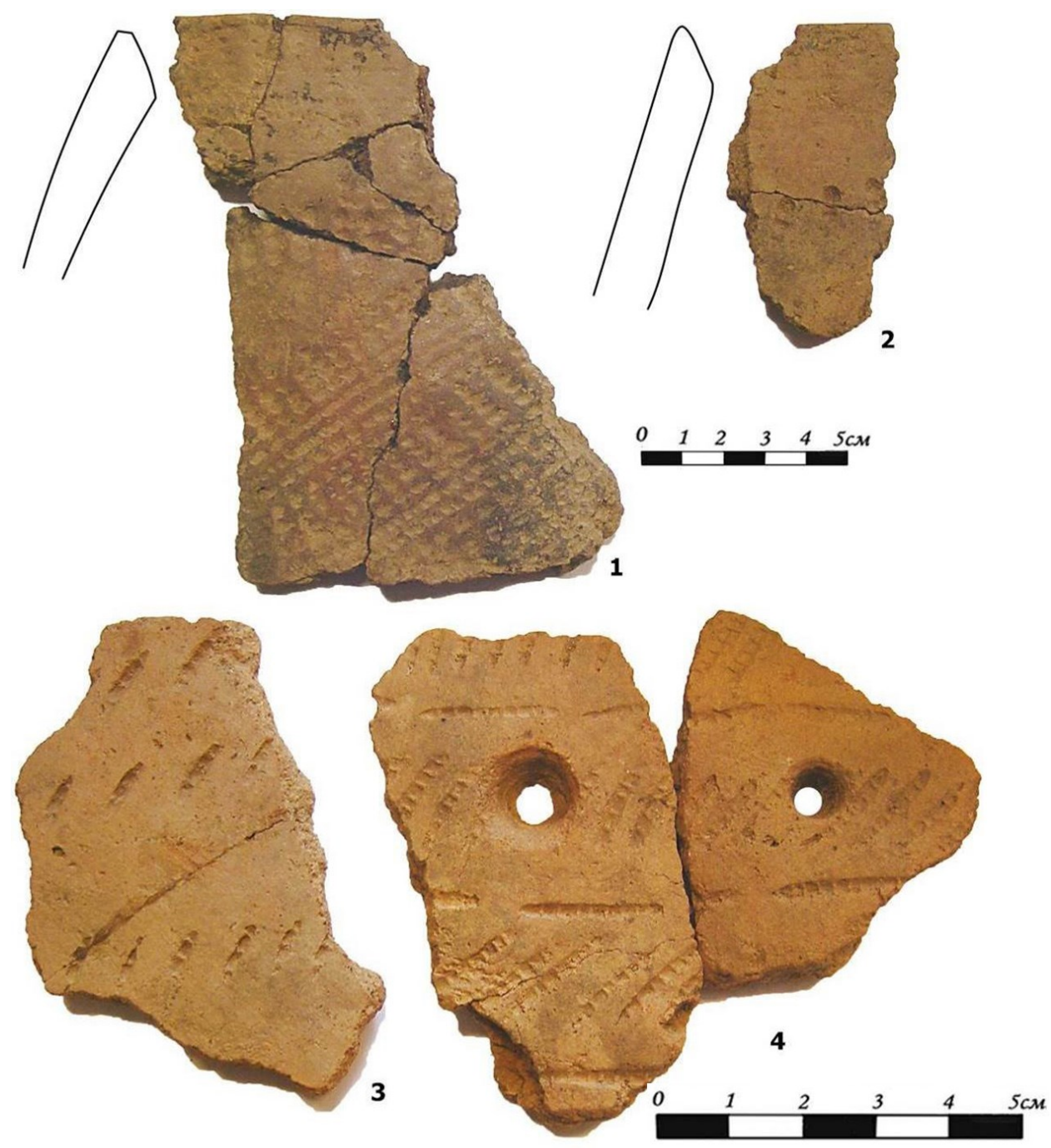

Рисунок 2 - Камская керамика.

1 - прокатывание гребенчатым штампом, 2-4- оттискивание гребенчатым штампом
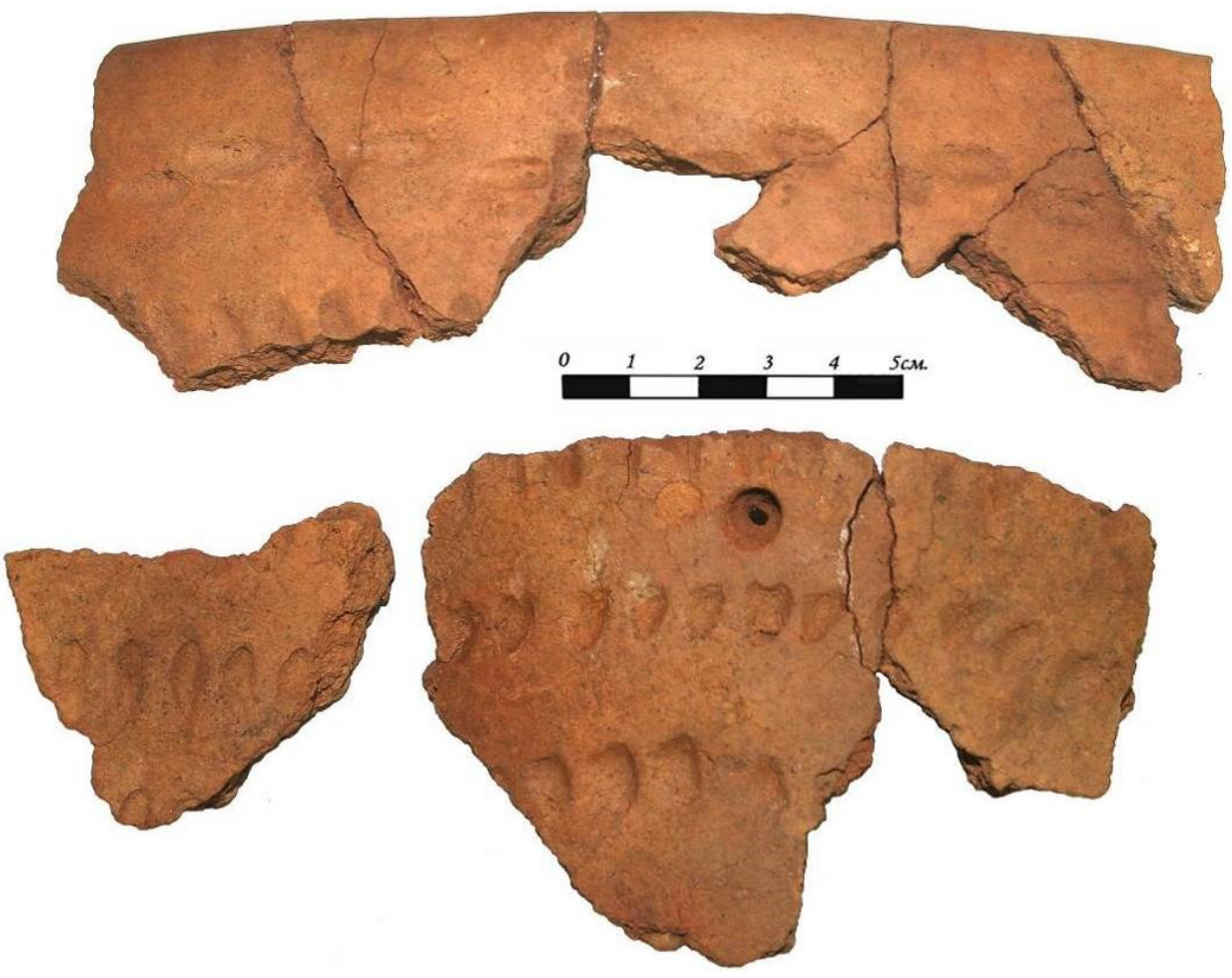

Рисунок 3 - Керамика новоильинской культуры 
В результате анализа формовочных масс нами были выделены рецепты двух групп - со смешанным многокомпонентным и с несмешанным двухкомпонентным составом. Составы ФМ представлены рецептами: илистые глины / глины + шамот; илистые глины / глины + органический раствор; илистые глины / глины + органический раствор + шамот. В первом и последнем составах шамот использовался в различных фракциях - как в мелких (>2,5 мм), так и крупных (<3 мм).

При сопоставлении результатов технико-технологического анализа с исследованием орнаментации нами были выделены некоторые особенности.

Основным способом нанесения орнамента при изготовлении посуды камской культуры выступает прокатывание, реже выделяется шагание, самый редкий способ орнаментации - оттискивание (табл. 1, рис. 1-2). Способы распространялись на сосуды, украшенные как гребенчатым, так и гладким штампом. Данное наблюдение не ново для посуды камской культуры [12; с. $15-21 ; 13$, с. $31-43 ; 14$, с. $318-325]$, однако нами была обнаружена следующая закономерность: посуда, изготовленная по рецептам ИПС + шамот или ИПС + органический раствор, украшалась, помимо гребенчатых оттисков, ямками и гладким штампом. В посуде с примесью органического раствора ямки наносились исключительно углом штампа, в то время как на сосуды с шамотом в формовочной массе они могли наноситься, как углом штампа, так и отдельным орудием с округлым рабочим концом. Так же стоит отметить, что в посуде с рецептом третьей группы (ИПС + шамот + органический раствор) ямоч- ная орнаментация отсутствует совсем - сосуды украшались только гребенчатыми отпечатками.

\section{Новоильинская культура}

Был произведен технико-технологический анализ 159 образцов керамики от разных сосудов, со следующих памятников: Новоильинское III (9), Чашкинское Озеро I (14), Тюремка I (2), Бойцово I (2), УстьОчер I (7), Зверево (10), Гагарская II (17), Гагарская III (33), Корепино (10),Усть-Паль (19), Заюрчим I (36).

При анализе материала определены следующие традиции: гончары использовали для изготовления посуды сырье в естественно увлажненном состоянии 98\% от всех изученных образцов, нет четкого разделения между илистой глиной и глиной, так как оба вида сырья применяли практически в равных долях. Преимущественно отбирали незапесоченное сырье: илистые глины (85\%), глины (80\%).

При анализе новоильинской посуды были выделены три рецепта ФМ второй и третьей группы [9, c. 68-75]. Наиболее распространенным был рецепт третьей группы - илистые глины/глины + органический раствор + шамот (142 сосуда - 89\%). Помимо него, были выделены рецепты с двухкомпонентным составом - илистая глина/глина + органический раствор (11 сосудов - 7\%), илистая глина/глина + шамот (5 сосудов - 3\%). При изготовлении ФМ с шамотом гончары использовали мелкую фракцию шамота (<3 мм).

При корреляции данных технико-технологического анализа с орнаментацией были получены следующие результаты (табл. 2).

таблица 1 - Соотношение формовочной массы с элементами орнамента. Камская культура

\begin{tabular}{|c|c|c|c|c|c|c|c|}
\hline \multirow{2}{*}{\multicolumn{2}{|c|}{ Орнаментация }} & \multicolumn{5}{|c|}{ Формовочная масса } & \multirow{2}{*}{ Итого } \\
\hline & & ИПС + Ш & ИПС + ОР & ИПС + OP + Ш & ИПС + Ш + ДГ & ИПС + ОР + ДГ & \\
\hline \multicolumn{2}{|c|}{ ОТ гребенки } & 4 & 1 & 3 & - & - & $8 / 17 \%$ \\
\hline \multirow{2}{*}{ ШАГ } & греб. & 4 & - & - & 1 & - & $5 / 11 \%$ \\
\hline & глад. & 2 & - & - & - & - & $2 / 4 \%$ \\
\hline \multicolumn{2}{|l|}{ ПР греб. } & 11 & 1 & 4 & - & 1 & $17 / 36 \%$ \\
\hline \multicolumn{2}{|c|}{ Ямки углом штампа } & 2 & - & - & - & - & $2 / 4 \%$ \\
\hline \multicolumn{2}{|c|}{ ПР + ШАГ } & 1 & - & - & - & - & $1 / 2 \%$ \\
\hline \multicolumn{2}{|c|}{ OT + ямки углом штампа } & 2 & - & - & - & - & $2 / 4 \%$ \\
\hline \multicolumn{2}{|c|}{ ШАГ + ямки } & 1 & - & - & - & - & $1 / 2 \%$ \\
\hline \multicolumn{2}{|c|}{ ШАГ + ямки углом штампа } & 1 & 2 & - & - & - & $3 / 6 \%$ \\
\hline \multicolumn{2}{|c|}{ ПР + ямки } & 1 & - & - & - & - & $1 / 2 \%$ \\
\hline \multicolumn{2}{|c|}{ ПР + ямки углом штампа } & 1 & 1 & - & - & - & $2 / 4 \%$ \\
\hline \multicolumn{2}{|c|}{ ШАГ (греб.) + ОТ греб. } & - & 1 & 2 & - & - & $3 / 6 \%$ \\
\hline \multicolumn{2}{|c|}{ ШАГ (греб.) + ОТ глад. } & - & - & 1 & - & - & $1 / 2 \%$ \\
\hline & Всего: & $30 / 63 \%$ & $6 / 12 \%$ & $10 / 21 \%$ & $1 / 2 \%$ & $1 / 2 \%$ & $48 / 100 \%$ \\
\hline
\end{tabular}

Примечания. $W$ - шамот; $O P$ - органический раствор; ДГ - дробленая глина; греб. - гребенчатый штамп; глад. - гладкий штамп; $O T$ - оттискивание; ПР - прокатывание; ШАГ - «шагающая гребенка».

Таблица 2 - Соотношение Формовочной Массы с элементами орнамента. Новоильинская культура

\begin{tabular}{|c|c|c|c|c|}
\hline \multirow{2}{*}{ Орнаментация } & \multicolumn{3}{|c|}{ Формовочная масса } & \multirow{2}{*}{ Итого } \\
\hline & ИПС + Ш & ИПС + ОР & ИПС + ОР + Ш & \\
\hline Греб. короткая (личинка) & 3 & 1 & 20 & $24 / 15 \%$ \\
\hline Греб. средняя (1,1-2,5 мм) & 4 & 3 & 39 & $46 / 30 \%$ \\
\hline Греб длинная & 4 & 1 & 35 & $37 / 24 \%$ \\
\hline Ямки & - & - & 7 & $7 / 4 \%$ \\
\hline Без орнамента & 1 & 1 & 2 & $4 / 2 \%$ \\
\hline Греб. короткая + греб. средн. & 1 & - & 17 & $18 / 11 \%$ \\
\hline Греб. короткая + ямки & - & - & 11 & $11 / 7 \%$ \\
\hline Греб. длинная + ямки & - & 1 & 7 & $8 / 5 \%$ \\
\hline Греб. (кор., средн., длин.) + ямки & - & 1 & 3 & $4 / 2 \%$ \\
\hline Всего: & $12 / 8 \%$ & $8 / 6 \%$ & $139 / 86 \%$ & $159 / 100 \%$ \\
\hline
\end{tabular}


Характерным способом нанесения орнамента на новоильинскую посуду является оттискивание штампа, редко встречается прокатывание, шагающая гребенка, как элемент, полностью исчезает. Керамика украшена гребенчатым штампом различной длины, на часть сосудов нанесены ямки (рис. 3). Сочетание нескольких элементов орнамента характерно в основном для рецептов илистая глина / глина + органический раствор + шамот, наиболее частые сочетания: короткий и средний гребенчатый штамп, короткий / длинный гребенчатый штамп и ямки. Стоит отметить, что не зафиксировано ямочного орнамента на сосудах, изготовленных из двухкомпонентного состава - илистая глина / глина + шамот.

\section{Заключение}

На основе проведенного технико-технологического анализа керамики неолитической камской и раннеэнеолитической новоильинской культур можно сделать следующие выводы. Во-первых, в производстве керамики обеих культур гончары использовали два вида сырья, отдавая небольшое преимущество илистым глинам (камская - 58\%, новоильинская 55\%). Схожая ситуация прослеживается на памятниках неолита-раннего энеолита сопредельных территорий $[15$, с. $212 ; 16]$. Этот факт может свидетельствовать о том, что гончары в то время не придавали большого значения различию свойств данных видов сырья. Однако, большое значение для отбора имела степень запесоченности. Представители обеих культур для изготовления посуды отбирали в основном незапесоченное/слабозапесоченное сырье. В навыках подготовки ИПС заметны различия: носители камской культуры чаще применяли сырье в дробленном состоянии, в то время как в новоильинской посуде этот прием зафиксирован только на одном памятнике в 4 образцах (2\%) (табл. 1,2$)$.

Во-вторых, на ступени подготовки формовочной массы, мы можем отметить, что для обеих культур

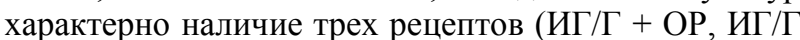
$+Ш, И Г / Г+$ ОР + Ш), различие заключается в том какой рецепт преобладает (в камской - ИПС + шамот; в новоильинской - ИПС + шамот + органический раствор). При изготовлении формовочной массы для создания камской посуды использовали в основном крупный шамот ( $<3$ мм), а для изготовления новоильинской посуды - мелкий ( $>2,5$ мм).

В-третьих, в ходе исследования нами было отмечено, что на позднем этапе существования камской культуры ямочная орнаментация использовалась гончарами лишь на сосудах с несмешанным двухкомпонентным составом: ИПС + органический раствор или ИПС + шамот, и совсем отсутствовала на сосудах со смешанным многокомпонентным составом: ИПС + органический раствор + шамот. В то время как, новоильинская посуда, украшенная гребенкой и ямками, была изготовлена из ФМ: ИПС + органический раствор + шамот. Для носителей традиции изготовления сосудов с рецептом ИПС + opганический раствор в коллекциях камской культуры было характерно нанесение ямок углом штампа, отсутствие специального орнаментира, может быть косвенным признаком зарождения традиции или ее копирования у местных групп населения. Гончары камской культуры использовали для ямочной орнаментации как штамп, так и отдельный инструмент, а новоильинской культуры использовали для нанесения ямочного орнамента только отдельные инструменты.
Резюмируя полученные результаты, можно сказать, что керамическая традиция новоильинской культуры складывалась на основе генезиса местной неолитической керамической традиции камской культуры с пришлым (Поволжским) компонентом. Для неолитической керамики Поволжья характерно использование илистых глин в естественном увлажненном состоянии, основной рецепт формовочной массы включает органический раствор и шамот в небольшой концентрации преимущественно до 3 мм [17, с. 70-80].

\section{Список литературы:}

1. Бобринский А.А. Гончарство Восточной Европы. Источники и методы изучения. М.: Наука, 1978. 272 с.

2. Бадер О.Н. Уральский неолит // Каменный век на территории СССР. М.: Изд-во: Наука, 1970. C. $157-171$.

3. Бадер О.Н. Третье Ново-Ильинское поселение // Отчеты Камской археологической экспедиции института археологии академии СССР. Москва, Вып. 2. M., 1961. C. 60-75.

4. Бобринский А.А. Гончарная технология как объект историко-культурного изучения // Актуальные проблемы изучения древнего гончарства: кол. монография. Самара: Изд-во СамГПУ, 1999. С. 5-109.

5. Васильева И.Н., Салугина Н.П. Экспериментальный метод в изучении древнего гончарства // Актуальные проблемы изучения древнего гончарства: кол. монография. Самара: изд-во Самар. гос. пед. унта, 1999. С. 181-198.

6. Васильева И.Н., Салугина Н.П. Некоторые итоги 18-летней работы Самарской экспедиции по экспериментальному изучению древнего гончарства // Труды II (XVIII) всерос. археологического съезда в Суздале (III). М.: Изд-во ИА РАН, 2008. С. 156-159.

7. Бобринский А.А., Васильева И.Н. О некоторых особенностях пластического сырья в истории гончарства // Проблемы древней истории Северного Прикаспия. Самара:Изд-во Самарского пед. ун-та. 1998. C. 203-205.

8. Васильева И.Н. О выделении камского ареала гончарных традиций эпохи неолита // Археология, этнография и антропология Евразии. № 4. 2011. C. $73-83$.

9. Цетлин Ю.Б. Древняя керамика. Теория и методы историко-культурного подхода. М.: ИАРАН, 2012. $430 \mathrm{c}$.

10. Цетлин Ю.Б. Керамика. Понятия и термины историко-культурного подхода. М.: ИА РАН. 2017. $346 \mathrm{c}$

11. Волкова Е.В. Орнаментальные традиции фатьяновских гончаров (опыт выделения субстратных и приспособительных традиций) // Древнее гончарство: итоги и перспективы изучения. М.: ИА РАН, 2010. С. $88-107$.

12. Батуева Н.С. Технико-технологический анализ керамики камской культуры // Вестник Научной ассоциации студентов и аспирантов исторического факультета Пермского государственного педагогического университета. Серия: Studia historica juvenum. Пермь: Перм. гос. пед. ун-т, 2017. С. 15-21.

13. Лычагина Е.Л. Результаты исследования неоэнеолитической керамики с гребенчатым орнаментом Чашкинского микрорегиона // Вестник Пермского университета. 2018. № 1. С. 31-43.

14. Лычагина Е.Л., Батуева Н.С. Технико-технологический анализ неолитической керамики камской культуры (по материалам памятников Верхнего и 
Среднего Прикамья) // XI Тверской археологический сборник. Тверь: ТГОМ, 2018, С. 318-325.

15. Андреева (Ересько) О.В. Сравнительный анализ ранних энеолитических комплексов Среднего Прикамья и лесного Среднего Поволжья (на основе технико-технологического анализа) // Известия Самарского научного центра РАН. 2018. Т. 20, № 3. С. 208-215.

16. Андреева О.В., Батуева Н.С. Соотношение гончарных традиций камской и новоильинской культур // Вестник Научной ассоциации студентов и аспирантов Исторического факультета Пермского государственного педагогического университета. Серия:
Studia historica juvenum: науч. журн. Пермь: Перм. гос. пед. ун-т, 2018. С. 11-21.

17. Васильева И.Н. Ранненеолитическое гончарство Волго-Уралья (по материалам Елшанской культуры) // Археология, этнография и антропология Евразии. 2 (46). 2011. С. 70-81.

Работа выполнена при поддержке гранта РФФИ № 18-39-00059 «Ранние гончарные традиции населения Среднего Предуралья». Работа выполнена в рамках государственного задания Министерства образования и науки РФ, проект № 33.1907.2017ПЧ.

\title{
THE POTTERY TRADITIONS OF LEVSHINSKIY STAGE OF THE KAMA NEOLITHIC AND NOVOILYINSKAYA ENEOLITHIC CULTURES
}

(C) 2019

\author{
Andreeva Olga Viktorovna, laboratory assistant of Research Department \\ Samara State University of Social Sciences and Education (Samara, Russian Federation) \\ Batueva Nadezhda Sergeevna, specialist of Scientific Department \\ Perm State Humanitarian Pedagogical University (Perm, Russian Federation)
}

Abstract. The following paper deals with the complexes of the late (Levshin) stage of the Kama culture and the early Eneolithic ceramic complexes of the Novoilyinskaya culture of the Middle Prikamye within the framework of a historical-cultural approach to the study of pottery. In the course of the work, the most stable traditions of raw material selection were highlighted: silty clay was used for the Kama culture; clay and silty clay were used in equal shares for the manufacture of Novoilyinskaya ceramics. For the manufacture of Kama ceramics raw materials were initially dried and crushed; this tradition was absent in the Novoilyinskaya culture. In both cultures mostly unsprayed (ductile) raw materials were used. As a result, it turned out that the population of the Kama region of the early Eneolithic was formed on the basis of the genesis of the local Neolithic population - the Kama culture representatives with the new (Volga) population. This fact may be indicated by differences in the skills of preparing plastic raw materials, mineral impurities for the preparation of the molding material, as well as the methods of applying the ornament.

Keywords: archeology; Neolithic; Eneolithic; historical and cultural approach; technical and technological analysis; Prikamye; Kama culture; Levshin type; Novoilyinskaya culture; ornament; archaeological ceramics; raw plastic materials; molding composition; clay; silty clay; fireclay; organic solution.

УДК 902/904 (476)

DOI 10.24411/2309-4370-2019-12204

Статья поступила в редакцию 21.01.2019

\section{РОЛЬ КУЛЬТУРЫ ШАРОВИДНЫХ АМФОР В РАЗВИТИИ СООБЩЕСТВ ВЕРХНЕГО ПОНЕМАНЬЯ}

(C) 2019

Вайтович Александра Владимировна, кандидат исторических наук,

доцент кафедры археологии и специальных исторических дисциплин

Белорусский государственный университет (2. Минск, Республика Беларусь)

Аннотация. В статье обобщаются результаты исследований, проведенных автором и другими специалистами, по проблеме присутствия культуры шаровидных амфор (далее КША) на территории Верхнего Понеманья. В соответствии с подходом М. Шмит, разработанным для восточноевропейских комплексов культуры, в рассматриваемом регионе идентифицированы «чистые» и «синкретические» материалы КША. К первой группе отнесены могильники КША, кремнедобывающие шахты и сопутствующие мастерские в Среднем Пороссье, а также отдельные находки кремневых четырехгранных шлифованных топоров и долот. Во вторую группу включены материалы неманской культуры и локальных групп круга шнуровой керамики с элементами, генетически восходящими к КША. Черты КША прослеживаются главным образом в орнаментации керамики. Присутствие отдельных групп населения, традиций КША в Верхнем Понеманье относится ко второй четверти III - первой четверти II тыс. до н.э. Распространение элементов КША в регионе осуществлялось в результате непосредственных контактов носителей различных культурных традиций или опосредованно через другие культуры, которые уже испытали влияние КША. В качестве потенциальных источников распространения элементов КША рассматриваются среднеднепровская культура и приморская (жуцевская) культура. В настоящее время приоритетными исследовательскими задачами являются уточнение хронологии распространения КША в регионе, установление роли КША в социально-экономических трансформациях сообществ III - начала II тыс. до н.э.

Ключевые слова: культура шаровидных амфор; неманская культура; круг культуры шнуровой керамики; погребения; кремнедобывающие шахты; керамика; орнамент; кремневые топоры и долота; признаки культуры; традиции; культурные процессы; заимствования; производящее хозяйство; поздний неолит; Республика Беларусь; Верхнее Понеманье. 